\title{
COMMUTING TRACES AND LIE ISOMORPHISMS ON GENERALIZED MATRIX ALGEBRAS
}

\author{
ZHANKUI XiAO AND FENG WEI
}

\begin{abstract}
Let $\mathscr{G}$ be a generalized matrix algebra over a commutative ring $\mathscr{R}, \mathfrak{q}: \mathscr{G} \times \mathscr{G} \longrightarrow \mathscr{G}$ be an $\mathscr{R}$-bilinear mapping and $\mathfrak{T}_{\mathfrak{q}}:: \mathscr{G} \longrightarrow \mathscr{G}$ be a trace of $\mathfrak{q}$. We describe the form of $\mathfrak{T}_{\mathfrak{q}}$ satisfying the condition $\mathfrak{T}_{\mathfrak{q}}(G) G=G \mathfrak{T}_{\mathfrak{q}}(G)$ for all $G \in \mathscr{G}$. The question of when $\mathfrak{T}_{\mathfrak{q}}$ has the proper form is considered. Using the aforementioned trace function, we establish sufficient conditions for each Lie isomorphism of $\mathscr{G}$ to be almost standard. As applications we characterize Lie isomorphisms of full matrix algebras, of triangular algebras and of certain unital algebras with nontrivial idempotents. Some further research topics related to current work are proposed at the end of this article.
\end{abstract}

Mathematics subject classification (2010): 15A78, 15A86, 16W10.

Keywords and phrases: Generalized matrix algebra, commuting trace, Lie isomorphism.

\section{REFERENCES}

[1] Z.-F. BAI, S.-P. DU AND J.-C. Hou, Multiplicative Lie isomorphisms between prime rings, Comm. Algebra, 36 (2008), 1626-1633.

[2] Z.-F. BAI, S.-P. DU AND J.-C. Hou, Multiplicative *-Lie isomorphisms between factors, J. Math. Anal. Appl., 346 (2008), 327-335.

[3] R. Banning And M. Mathieu, Commutativity preserving mappings on semiprime rings, Comm. Algebra, 25 (1997), 247-265.

[4] K. I. BEIDAR, M. BREŠAR AND M. A. CheBotAR, Functional identities on upper triangular matrix algebras, J. Math. Sci., 102 (2000) 4557-4565.

[5] K. I. Beidar, M. Brešar, M. A. Chebotar and W. S. Martindale, 3Rd, On Herstein's Lie map conjectures, III, J. Algebra, 249 (2002), 59-94.

[6] K. I. BeidAR, W. S. MARTINDAle, 3RD AND A. V. MiKhalev, Lie isomorphisms in prime rings with involution, J. Algebra, 169 (1994), 304-327.

[7] D. Benkovič, Lie derivations on triangular matrices, Linear Multilinear Algebra, 55 (2007), 619 626.

[8] D. BenKoviČ, Biderivations of triangular algebras, Linear Algebra Appl., 431 (2009), 1587-1602.

[9] D. BENKOVIČ, Generalized Lie derivations on triangular algebras, Linear Algebra Appl., 434 (2011), $1532-1544$.

[10] D. Benkovič, Lie triple derivations on triangular matrices, Algebra Colloq., 18 (2011), Special Issue No. 1, 819-826.

[11] D. BenKoviČ AND D. EREMITA, Commuting traces and commmutativity preserving maps on triangular algebras, J. Algebra, 280 (2004), 797-824.

[12] D. BenKoviČ AND D. EREMITA, Multiplicative Lie n-derivations of triangular rings, Linear Algebra Appl., 436 (2012), 4223-4240.

[13] P. S. BLAU, Lie isomorphisms of prime rings, Ph. D. Thesis, University of Massachusetts Amherst, 1996, 68 pp.

[14] P. S. BLAU, Lie isomorphisms of non-GPI rings with involution, Comm. Algebra, 27 (1999), 23452373.

[15] M. BrešAR, On a generalization of the notion of centralizing mappings, Proc. Amer. Math. Soc., 114 (1992), 641-649. 
[16] M. BREŠAR, Commuting traces of biadditive mappings, commutativity-preserving mappings and Lie mappings, Trans. Amer. Math. Soc., 335 (1993), 525-546.

[17] M. BREŠAR, Centralizing mappings and derivations in prime rings, J. Algebra, 156 (1993), 385-394.

[18] M. BReŠAR, Commuting maps: a survey, Taiwanese J. Math., 8 (2004), 361-397.

[19] M. BREŠAR AND P. ŠEMrL, Commuting traces of biadditive maps revisited, Comm. Algebra, 31 (2003), 381-388.

[20] W. P. BRown, Generalized matrix algebras, Canad. J. Math., 7 (1955), 188-190.

[21] A. J. CALDERón MARTín AND C. MARTín GONZÁLEZ, Lie isomorphisms on $H^{*}$-algebras, Comm. Algebra, 31 (2003), 323-333.

[22] A. J. CAlderón Martín And C. Martín GonZÁlez, The Banach-Lie group of Lie triple automorphisms of an $H^{*}$-algebra, Acta Math. Sci. (Ser. English), 30 (2010), 1219-1226.

[23] A. J. CALderón MARTín AND C. Martín GonZÁlez, A linear approach to Lie triple automorphisms of $H^{*}$-algebras, J. Korean Math. Soc., 48 (2011), 117-132.

[24] A. J. Calderón Martín And M. Haralampidou, Lie mappings on locally $m$-convex $H^{*}$ algebras, International Conference on Topological Algebras and their Applications. ICTAA 2008, 42-51, Math. Stud. (Tartu), 4, Est. Math. Soc., Tartu, 2008.

[25] W. S. Cheung, Maps on triangular algebras, Ph. D. Dissertation, University of Victoria, 2000. 172 pp.

[26] W. S. Cheung, Commuting maps of triangular algebras, J. London Math. Soc., 63 (2001), 117-127.

[27] W. S. Cheung, Lie derivations of triangular algebras, Linear Multilinear Algebra, 51 (2003), 299310.

[28] D. Ž. Doković, Automorphisms of the Lie algebra of upper triangular matrices over a connected commutative ring, J. Algebra, 170 (1994), 101-110.

[29] G. DolinaR, Maps on upper triangular matrices preserving Lie products, Linear Multilinear Algebra, 55 (2007), 191-198.

[30] G. DolinaR, Maps on $M_{n}$ preserving Lie products, Publ. Math. Debrecen, 71 (2007), 467-477.

[31] Y. DU AND Y. WANG, Lie derivations of generalized matrix algebras, Linear Algebra Appl., 437 (2012), 2719-2726.

[32] I. N. HeRstein, Lie and Jordan structures in simple, associative rings, Bull. Amer. Math. Soc., 67 (1961), 517-531.

[33] L. HUA, A theorem on matrices over an sfield and its applications, J. Chinese Math. Soc. (N.S.), 1 (1951), 110-163.

[34] P. A. KRYLOV, Isomorphism of genralized matrix rings, Algebra and Logic, 47 (2008), 258-262.

[35] P.-H. LeE, T.-L. Wong, J.-S. Lin AND R.-J. WANG, Commuting traces of multiadditive mappings, J. Algebra, 193 (1997), 709-723.

[36] Y.-B. Li AND F. WEI, Semi-centralizing maps of genralized matrix algebras, Linear Algebra Appl., 436 (2012), 1122-1153.

[37] Y.-B. LI, L. VAN WYK AND F. WEI, Jordan derivations and antiderivations of genralized matrix algebras, Oper. Matrices, 7 (2013), 399-415.

[38] Z.-K. XiAo, F. WeI, Centralizing traces and Lie triple isomorphisms on triangular algebras, Preprint.

[39] F.-Y. Lu, Lie isomorphisms of reflexive algebras, J. Funct. Anal., 240 (2006), 84-104.

[40] L. W. MARCOUX AND A. R. SOUROUR, Commutativity preserving maps and Lie automorphisms of triangular matrix algebras, Linear Algebra Appl., 288 (1999), 89-104.

[41] L. W. Marcoux AND A. R. Sourour, Lie isomorphisms of nest algebras, J. Funct. Anal., 164 (1999), 163-180.

[42] W. S. Martindale, 3RD, Lie isomorphisms of primitive rings, Proc. Amer. Math. Soc., 14 (1963), 909-916.

[43] W. S. MARTindale, 3RD, Lie isomorphisms of simple rings, J. London Math. Soc., 44 (1969), $213-$ 221.

[44] W. S. Martindale, 3RD, Prime rings satisfying a generalized polynomial identity, J. Algebra, 12 (1969), 576-584.

[45] W. S. Martindale, 3RD, Lie isomorphisms of prime rings, Trans. Amer. Math. Soc., 142 (1969), 437-455. 
[46] W. S. MARTINDALE, 3RD, Lie and Jordan mappings in associative rings, Ring theory (Proc. Conf., Ohio Univ., Athens, Ohio, 1976), pp. 71-84. Lecture Notes in Pure and Appl. Math., Vol. 25, Dekker, New York, 1977.

[47] W. S. Martindale, 3RD, Lie and Jordan mappings, Contemporary Math., 13 (1982), 173-177.

[48] W. S. MARTINDALE, 3RD, Lie maps in prime rings: a personal perspective, Rings and Nearrings, 95-110, Walter de Gruyter, Berlin, 2007.

[49] M. Mathieu, Lie mappings of $C^{*}$-algebras, Nonassociative algebra and its applications, 229-234, Lecture Notes in Pure and Appl. Math., 211, Dekker, New York, 2000.

[50] C. R. Miers, Lie isomorphisms of factors, Trans. Amer. Math. Soc., 147 (1970), 55-63.

[51] C. R. Miers, Lie homomorphsism of operator algebras, Pacific J. Math., 38 (1971), 717-735.

[52] C. R. Miers, Lie triple derivations of von Neumann algebras, Proc. Amer. Math. Soc., 71 (1978), $57-61$.

[53] K. MORITA, Duality for modules and its applications to the theory of rings with minimum condition, Sci. Rep. Tokyo Kyoiku Diagaku Sect. A, 6 (1958), 83-142.

[54] X.-F. QI AND J.-C. Hou, Characterization of $\xi$-Lie multiplicative isomorphisms, Oper. Matrices, 4 (2010), 417-429.

[55] X.-F. QI AND J.-C. Hou, Characterization of Lie multiplicative isomorphisms between nest algebras, Sci. China Math., 54 (2011), 2453-2462.

[56] M. P. Rosen, Isomorphisms of a certain class of prime Lie rings, J. Algebra, 89 (1984), 291-317.

[57] P. ŠEmRL, Non-linear commutativity preserving maps, Acta Sci. Math. (Szeged), 71 (2005), 781-819.

[58] A. R. Sourour, Maps on triangular matrix algebras, Problems in applied mathematics and computational intelligence, 92-96, Math. Comput. Sci. Eng., World Sci. Eng. Soc. Press, Athens, 2001.

[59] T. WANG AND F.-Y. LU, Lie isomorphisms of nest algebras on Banach spaces, J. Math. Anal. Appl., 391 (2012), 582-594.

[60] Z.-K. XIAO AND F. WEI, Commuting mappings of generalized matrix algebras, Linear Algebra Apll., 433 (2010), 2178-2197.

[61] X.-P. YU AND F.-Y. LU, Maps preserving Lie product on B(X), Taiwanese J. Math., 12 (2008), $793-806$.

[62] J.-H. ZhANG AND F.-J. ZhANG, Nonlinear maps preserving Lie products on factor von Neumann algebras, Linear Algebra Appl., 429 (2008), 18-30. 